K. FUKUDA ${ }^{1, \infty}$

M. KINOSHITA ${ }^{2}$

M. TACHIKAWA ${ }^{3}$

\section{Allan-variance measurements of diode laser frequency-stabilized with a thin vapor cell}

${ }^{1}$ Applied Research and Standards Division, Communications Research Laboratory, 4-2-1 Nukuikita-machi, Koganei, Tokyo 184-8795, Japan

${ }^{2}$ University of Tokyo, 5-1-5 Kashiwanoha, Kashiwa, Chiba 277-8581, Japan

${ }^{3}$ Department of Physics, Meiji University, 1-1-1 Higashimita, Tama-ku, Kawasaki, Kanagawa 214-8571, Japan
Appl. Phys. B (2003)

DOI 10.1007/s00340-003-1286-4

Published online: 30 September 2003

Unfortunately, the author affiliations were originally published out of order. They now appear correctly above. 